\title{
Correction to: Differential effects of different delivery methods on progression to severe postpartum hemorrhage between Chinese nulliparous and multiparous women: a retrospective cohort study
}

\author{
Chang $\mathrm{Xu}^{1+}$, Wanting Zhong ${ }^{2 \dagger}$, Qiang Fu ${ }^{3}$, Li Yi ${ }^{1}$, Yuqing Deng ${ }^{1}$, Zhaohui Cheng ${ }^{4}$, Xiaojun Lin ${ }^{5}$, Miao Cai ${ }^{3}$,
} Shilin Zhong ${ }^{1}$, Manli Wang ${ }^{6 *}$, Hongbing Tao ${ }^{7}$, Haoling Xiong ${ }^{7}$, Xin Jiang ${ }^{1}$ and Yun Chen ${ }^{1}$

\section{Correction to: BMC Pregnancy Childbirth 20, 660 (2020) https://doi.org/10.1186/s12884-020-03351-7}

Following publication of the original article [1], the authors informed us that the first affiliation has been provided incorrectly. In this Correction, correct and incorrect version is shown.

Incorrect: "Department of medical administration, Beijing University Shenzhen Hospital, Shenzhen 518036, China."

Correct: "Peking University Shenzhen Hospital, Shenzhen 518036, China."

The original article has been corrected.

\begin{abstract}
Author details
${ }^{1}$ Peking University Shenzhen Hospital, Shenzhen 518036, China. ${ }^{2}$ Department of Medical Administration, Zhuhai People's Hospital (Zhuhai Hospital Affiliated with Jinan University), Zhuhai 519000, China. ${ }^{3}$ Department of Epidemiology and Biostatistics, College for Public Health and Social Justice, Saint Louis University, St. Louis, MO 63013, USA. ${ }^{4}$ Department of Health Statistics and Research Development, Chongqing Health Information Center, Chongqing 401120, China. ${ }^{5}$ West China School of Public Health and West China Fourth Hospital, Sichuan University, Chengdu 610041, China. ${ }^{6}$ China Center for Special Economic Zone Research, Shenzhen University, Shenzhen 518060, Guangdong, China. ${ }^{7}$ School of Medicine and Health Management,
\end{abstract}

Tongji Medical College, Huazhong University of Science and Technology, Wuhan 430016, China.

Published online: 19 January 2021

\section{Reference}

1. Xu, et al. BMC Pregnancy Childbirth. 2020;20:660. https://doi.org/10.1186/ s12884-020-03351-7.

The original article can be found online at https://doi.org/10.1186/s12884020-03351-7.

* Correspondence: wangmanli1237@hust.edu.cn

${ }^{\dagger}$ Chang Xu and Wanting Zhong contributed to this work equally and should be regarded as co-first authors.

${ }^{6}$ China Center for Special Economic Zone Research, Shenzhen University, Shenzhen 518060, Guangdong, China

Full list of author information is available at the end of the article

(c) The Author(s). 2021 Open Access This article is licensed under a Creative Commons Attribution 4.0 International License, which permits use, sharing, adaptation, distribution and reproduction in any medium or format, as long as you give appropriate credit to the original author(s) and the source, provide a link to the Creative Commons licence, and indicate if changes were made. The images or other third party material in this article are included in the article's Creative Commons licence, unless indicated otherwise in a credit line to the material. If material is not included in the article's Creative Commons licence and your intended use is not permitted by statutory regulation or exceeds the permitted use, you will need to obtain permission directly from the copyright holder. To view a copy of this licence, visit http://creativecommons.org/licenses/by/4.0/ The Creative Commons Public Domain Dedication waiver (http://creativecommons.org/publicdomain/zero/1.0/) applies to the data made available in this article, unless otherwise stated in a credit line to the data. 